\title{
Educating Engineers for Rebuilding Rather Than Building
}

\author{
ROBERT D. HANSON \\ Department of Civil Engineering \\ University of Michigan \\ 304 West Engineering Building \\ Ann Arbor, Michigan 48109
}

The subject of this New York Conference on the Infrastructure: Maintenance and Repair of Public Works is timely. The broad-based view represented by the speakers which covers government policies, public financing, influence of maintenance and repair on building codes and standards, and the recognition that reconstruction requires different technological innovations is particularly pertinent to this session on civil engineering education and research. The purpose of this paper is to discuss what civil engineering educators and researchers must do to prepare new engineers for these new challenges.

The United States has had a relatively unique position in the technological development arena. Many of our cities and public works were initiated and expanded while the new technologies were being created and improved. Our transportation systems evolved through waterway systems including canals, railroads, auto and truck traffic on dirt roads, and paved highways and expressways, and by air. In almost all of these cases the newest of the technology was applied as additions to or replacements for existing systems. Many parallels exist for water supply and waste treatment. The same is also true for our buildings. The evolution of building technology from timber, stone, and brick through iron, concrete, steel, aluminum, and prestressing has in general left us with a broad supply of building types and materials. Historically, when new facilities were needed the old facilities would be demolished and replaced by newer, bigger, better facilities.

Design analysis has had a similar history. Each step of the evolution from simple design analysis procedures through the more complex interconnected systems designs now common followed the development of new analytical capabilities. Even though we now need large digital computers to effectively use our analytical capabilities for the particular problem being studied, we should not forget that earlier designers faced the same decisions that we do now. Many public of ficials and engineers, not too many years ago, firmly believed that the results of a computer simulation provided the answer for their decisions. At the present time there is a growing recognition that computer modeling and input data are not sufficient to provide the final answer in all cases. However, reevaluation of our past experiences based on current knowledge is necessary. Interaction between our real nonlinear, nonelastic, 
complex behavior and the variations of these behaviors over time and over operating conditions is necessary to improve the models for our sophisticated computer programs. All of this requires increased data storage and time for interpretation and evaluation of existing data.

Our design codes and material specifications have followed a similar process of development based upon actual practice and observational experience of systems during their effective lifetimes. Quality control and quality assurance in the construction process and increased trust in our analytical capabilities have continued to lower the factor of safety designed into these systems. It is important for us to recognize that over 150 years of engineering education has been built on the premise that we learn from the past in terms of material, analytical, and construction behavior characteristics for the design, specification, and construction of new facilities to serve specific objectives. I repeat, construction of new facilities. As stated by the speakers at this conference, it is not politically possible or economically beneficial to continue the previous policy of demolishing the old and replacing them by new facilities.

At this point I will narrow the focus of this discussion to buildings as a subset of the general topic of public works. A further focus will exclude buildings of historical significance because they allow (or require) decisions somewhat independent of economics. More specifically, let us look at one class of public buildings which is becoming more and more important to public of ficials - the public schools. The public school building may have been built in the late 1800 s or early 1900 s utilizing a single or mixed mode of construction involving brick, timber, reinforced concrete, iron, and roof tile. In many cases the building may have undergone a number of periods of remodeling in which hollow concrete block, plywood, sheet rock, wood studs, or metal studs have been utilized to change the function or to modernize certain spaces in the building. The windows may be single-paned glass in wood casements, and the stairways would be of wood or iron with tile, granite, or concrete treads. The human occupancy environment is excellent in terms of deterioration of the building materials, but the maintenance of the structure may have been poor or nonexistent, especially in recent years. Roof leaks may have allowed water to penetrate into the roof supports, the ceilings, and even into the masonry walls. This water intrusion causes a rapid deterioration of the building materials and, if not fixed in time, can result in failure of the building.

The architectural changes in the building may have been cosmetic in nature or in some cases may actually have provided local stiffnesses and strength to the building. The first problem the engineering designer is faced with is an assessment and evaluation of the building's current state. When was the original structure built? With that information a determination of the applicable building codes, material performance characteristics, and reputation of the original designer and constructor will provide an initial judgment of the structure. What changes have been made since initial construction? Again the applicable building codes, material performance characteristics, and reputation of the designer and constructor are crucial to the assessment of the current building. What environmental conditions, loading conditions, and 
maintenance has the building seen? This is needed to assess the probable deterioration of the building materials throughout the life of the structure. In some cases these effects may be small so that the original material characteristics can be used for the current evaluation. In other cases the effects of deterioration may be so major that an assessment of the original strength may have no effect on its current characteristics. Most cases are not at these two extremes.

A word of caution must be given to those who have not been involved in many cases of rehabilitation or strengthening. The official file plans, if they exist, may not accurately reflect the details of the actual construction. This is not to imply fraud by the constructor or building inspector, rather it reflects the difference between field conditions and those assumed by the designer. The differences are sometimes noted on the drawings. Some drawings may be nothing more than architectural plans with general dimensions and types of materials indicated.

In summary, what the structural engineer needs are techniques whereby the current structural characteristics can be evaluated. From this evaluation an assessment of the proposed rebuilding can be made. Not all of the tools needed to efficiently perform this evaluation and assessment are available at the present time. This will be addressed later when research is discussed.

There have been very few educational programs that have addressed the issues of rebuilding and rehabilitating existing facilities. The most common ones have been "short courses" directed toward the design professionals and taught by other design professionals. Most of our engineering colleges do an excellent job of educating their students for design of new facilities using the most up-to-date materials, processes, and techniques and incorporating the most recent of the national building codes and materials specifications. What cannot be taught effectively in the colleges is the performance experience that practicing engineers develop by observing their designs in practice and their observations of real building performance under different loading histories and maintenance conditions. I believe that most employers of recent graduates are reasonably satisfied by the content of the education provided. The fact that not all colleges approach the area of design in the same way is important so that each employer can obtain the diversity of backgrounds necessary for a strong organization. Nevertheless, there are a few philosphical concepts that every college can implement to significantly upgrade their graduates' capabilities to solve the complex problems created by the need to rebuild rather than build new.

The approach that has been used by the University of Michigan Civil Engineering Structures' Faculty to prepare their students for these types of problems has been twofold. First, the main emphasis for analysis and design is that the student develops an understanding for the real behavior of the structural system and the materials used in the system. One of the keys to developing this understanding is that the student is able to follow the behavior of the structure and its elements from the small deformation elastic response through its damage level behavior until failure. As much as possible these behavioral experiences come from real structures; that is, examples of real structure be- 
havior are studied and correlated to behavior that would have been expected based upon previous experiences, theories, and laboratory studies. All of the faculty members have been involved with laboratory tests, at many scales, and to varying degrees with observations of real building failures. Earthquakedamaged buildings provide one of the largest groups of buildings for these studies. The major difficulty with using earthquake-damaged buildings is that the loading condition is not precisely known. However, from a series of studies an understanding of the sequential damage conditions becomes clear. Buildings subjected to other types of overloads are also valuable in this regard. Buildings damaged during construction or with damage caused by design or construction errors are not a very good source of data because most of the concerned parties wish to restrict the information.

These real building data are supplemented by laboratory test data. It is important for the student to have hands-on experience with damaged materials and structural systems. Without this experience the student does not have the ability to assess and interpret written and photographic descriptions of damaged real buildings. This hands-on experience has to be closely coupled with appropriate theoretical and computer model studies. Then both the physical and mathematical results are interpreted in light of the current building codes and specifications.

Second, research studies into the behavior of various methods of repair and strengthening of structural elements and systems need to be carried out. These studies serve two purposes. They provide data needed by the design professionals, and they provide physical observations needed by the students. It is unfortunate that many of the rebuilding systems are designed and constructed on the basis of theoretical investigations and without physical tests to verify the expected behavior.

Laboratory research as described above can provide valuable data as well as valuable educational experiences. It can also provide a means for evaluating various techniques for assessing field measurements of material properties. A number of research efforts in the repair and strengthening of buildings for increased earthquake resistance have provided data useful in material properties evaluation. Seminars that bring together design and construction professionals and researchers have proven to be an excellent method to quickly raise the state of the art.

If the question is, What should civil engineering educators be doing to prepare their students for the challenges of rebuilding the infrastructure? then the answer is, Provide the students with hands-on physical experience to couple with their existing theoretical and mathematical abilities. With a full appreciation of the real behavior of the physical system and how that compares with the mathematical simulations, the design professionals will be able to create innovative solutions to their problems. They will be able to develop solutions that may not literally satisfy the codes, but that can be demonstrated to more than satisfy the full intent of the codes. This physical experience will also encourage design professionals to use experimental research to answer questions and suggest solutions not conveniently solved by theoretical methods alone. Civil engineering education needs to reemphasize physical laboratory 
experiences and to tie those experiences closely to real operating system characteristics and to computer simulations of the same systems.

\section{DISCUSSION OF THE PAPER}

P. L. Rinaldi (Port Authority of New York and New Jersey, New York, N.Y.): Before coming to the Port Authority, I taught civil engineering for several years. It seems that we do a reasonably good job in our engineering education institutions in teaching the basic tools we need to do engineering. When we couple that with application of those tools in the undergraduate curriculum we seem to focus on building new and putting systems in place that are new. Many of us now that are practicing engineering find that those tools have to be applied in a different way. Yet when we try and fall back on some of the examples that we learned in our academic days, they don't apply because we've been taught to look at building new systems rather than rebuilding systems.

You have mentioned that what can't be taught in the colleges is the performance experience that engineers get in practice. I differ with you in that we can do that. It seems that what we tend to do is recruit faculty for our educational institutions with an emphasis on academic credentials and to the exclusion of practical experience. And if anything, in rebuilding infrastructure, practical experience is a very key thing that should be shared with students as they go through the civil engineering curriculum. It's something that we haven't been doing. Adjunct professors with many years of experience teaching courses do lend themselves to this very well. What I ask Dr. Hanson is, What could you recommend or what have you done in your department and at the University of Michigan (1) to change the curriculum to focus the curriculum more on rebuilding and (2) in recruiting or putting in place a faculty that can adequately do that?

R. D. HANSON: I find your comments very appropriate. However, I disagree a little bit with some of the conclusions that you reach from those same observations with which I agree. Because the employers for which we are educating our students have a broad range of needs it is not always possible to give them the essential observational information in an academic environment. We do use adjuncts, we do provide our students with hands-on experiences as much as we can. However, there's a limited amount of time within any educational program. Our firm belief of what we want to do is to educate an engineer to have the capability of thinking and understanding the behavior of a system whether it be a structural system, a water supply system, or a transportation system so that an entire overview from the mathematical simulation aspects to the practical, physical interpretation is understood. We don't have the time to take very many specific examples and try to apply them.

The other aspect of engineering education, and one that I'm very strongly supportive of, is that not every engineering school should be doing the same 
thing. I think we need engineering schools that cover the entire range of the engineering profession. Those that are directed more toward research applications and those that are directed more for immediate engineering design applications. We need the whole spectrum of background and viewpoint, and that's why I have tried to emphasize that the firms hiring these engineers should hire them from many different sources so that they build a strong organization with different points of view and different experiences coming out of the educational environment. Not every school can cover the entire area in the way that both you and I feel it has to be covered. 